EESTI NSV TEADUSTE AKADEEMIA TOIMETISED. 25. KOIDE

FOUSIKA * MATEMAATIKA. 1976, NR. 4

ИЗВЕСТИЯ АКАДЕМИИ НАУК ЭСТОНСКОИ ССР. ТОМ 25 ФИЗИКА * МАТЕМАТИКА, 1976, № 4

\title{
NMR SIDEBAND STRUCTURE OF AN ANNULAR SPINNING SAMPLE
}

An annular spinning NMR sample with of coils not covering the whole sample, is the intermediate case between a conventional spinning sample and a flowing one. In this case a specific structure of sidebands arises from the periodical interaction of sample particles and $r f$ coils. The frequency of all these sideband signals is that of the exciting $r f$ field in spite of their appearance at different values of the polarizing field.

\section{Introduction}

In a conventional nuclear magnetic resonance (NMR) spinning sample, the particles of the sample circle, while all the points of each particular circle have identical (or very nearly identical) coupling to the rf coil(s) of a probe head. The alternative kind of moving sample is a liquid which flows only once through the rf coil(s). Periodic use is sometimes the case, but the period is then longer than the nuclear spin-lattice relaxation time $T_{1}$.

The spinning of a sample is often used to diminish the line broadening due to the inhomogeneity of the polarizing field $H_{0}$. It averages out some of $H_{0}$ gradients, however, by-products - small spinning sidebands - are produced (due to the same $H_{0}$ gradients). In a flowing sample, somewhat similarly, some of $H_{0}$ gradients along the velocity vector are averaged out, but no kind of sidebands is present. A more marked feature is the line broadening $\Delta \omega \approx 1 / \tau_{i}$, where $\tau_{i}$ stands for the time of flowing a sample particle through a $r f$ coil $\left[{ }^{1}\right]$. Yet another feature is line shift, but it occurs only in some flow patterns. The last feature was discussed in detail by Borodin $\left[{ }^{2}\right]$ and called "kinematic relativity".

The present paper has to deal with an intermediate kind of moving sample. In this case, particles of a sample move periodically through the $r f$ coil(s), with a sufficiently short period $T_{r}<T_{2}{ }^{*}$, where $T_{2}{ }^{*}$ denotes some effective transversal relaxation time. We are not aware of investigations concerning this case. Such a periodical moving is conveniently produced by a rotating disk, where sample(s) can be placed in a peripheral groove(s) of this disk, and an important special case and the most practical one at that is the annular sample.

Prior to this investigation we thought that such a periodically interacting sample must have somewhat intermediate characteristics between usual spinning and flowing samples, but this was not the case. A particularly confusing point was - over which region we should average the field $H_{0}$ to determine the resonance frequency, over the span of the transmitter coil, or the receiver coil, or elsewhere. 


\section{General case}

A NMR sample $d V$ (Fig. 1) circles around an axle $O$ and moves periodically through a transmitter coil $C$ and a receiver coil $B$, all axes being perpendicular to the plane of drawing. The angle $\varphi_{a}$ between coils is quite arbitrary, including $\varphi_{a}=0$ (single coil system). One assumes that relaxation effects during one period of rotation $T_{r}=2 \pi / \Omega$ are negligible: $T_{r} \ll T_{1} ; T_{r} \varphi_{a} / 2 \pi \ll T_{2} *$. The transmitter coil produces an oscillating $r f$ field

$$
\mathbf{H}_{1}^{\mathrm{c}}=\mathbf{i} 2 H_{1}^{\mathrm{c}} \cos \omega_{1} t .
$$

The sample $d V$ during the course of its moving through the $C$-coil senses the $r f$ field $\mathbf{H}_{1}(t)$ in the form of pulses of the amplitude $2 H_{1}^{c}$, of the duration $\tau_{c}=T_{r \varphi c} / 2 \pi$, and of the period $T_{r}$. The amplitude of $\mathbf{H}_{1}(t)$ can be written by its

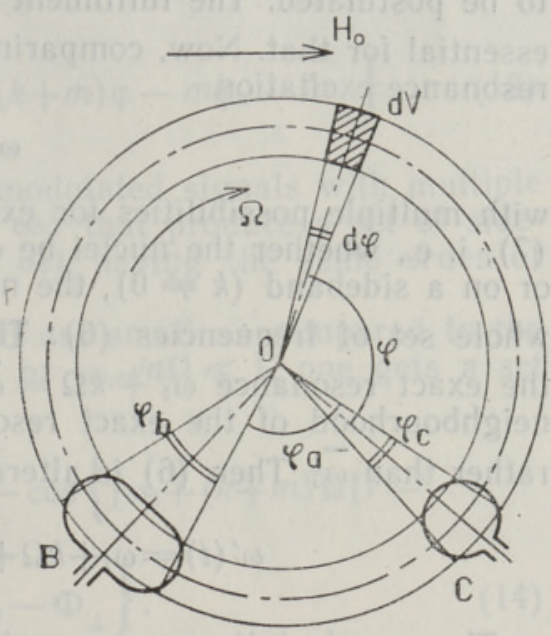

Fig. 1. $d V$ is rotating differential NMR sample, $C$ is transmitter coil, and $B$ is receiver coil. Fourier expansion

$$
H_{1}(t)=H_{1,0}+2 \sum_{k=1}^{\infty} H_{1, k} \cos (k \Omega t-k \varphi)
$$

with coefficients

$$
H_{1,0}=H_{1}^{c} \frac{\varphi_{c}}{2 \pi} ; \quad H_{1, k}=\frac{H_{1}{ }^{c}}{k \pi} \sin k \frac{\varphi_{\mathrm{c}}}{2} .
$$

Thus the $r f$ field as sensed by the sample

$$
\mathbf{H}_{1}(t)=\mathrm{i} 2 \sum_{k=-\infty}^{\infty} H_{1, k} \cos \left[\left(\omega_{1}+k \Omega\right) t-k \varphi\right] .
$$

The next step is to consider the influence of an inhomogeneous polarizing field $H_{0}$. For the sample $d V$ this field becomes time dependent, $H_{0}(t)$, and having the same period $T_{r}$. This periodicity enables again a Fourier expansion of $H_{0}(t)$ to be written:

$$
H_{0}(t)=\bar{H}_{0}+\sum_{n=1}^{\infty} H_{0, n} \cos \left(n \Omega t-\varphi_{n}\right),
$$

where $\bar{H}_{0}$ is the mean value of the field $H_{0}$ over the path of rotation and $H_{0, n}$ are essentially the amplitudes of field gradients of the same order $n$ (in polar coordinates). A corresponding time dependent (instantaneous) resonance frequency is

$$
\omega_{0}(t)=\bar{\omega}_{0}+\sum_{n=1}^{\infty} \omega_{0, n} \cos \left(n \Omega t-\varphi_{n}\right),
$$

where $\bar{\omega}_{0}=\gamma \bar{H}_{0} \quad(\gamma-$ magnetogyric ratio of nuclei $)$ represents the mean value of the resonance frequency and $\omega_{0, n}=\gamma H_{0, n}$ are deviation amplitudes. 
To get useable results, a resolved structure of frequencies $\omega_{1}+k \Omega$ is to be postulated. The fulfilment of conditions $\Omega \gg 1 / T_{2}^{*}$ and $\Omega \gg\left|\gamma H_{1, k}\right|$ is essential for that. Now, comparing (4) with (6) one gets the condition of resonance excitation

$$
\omega_{1}+k \Omega \approx \bar{\omega}_{0}
$$

with multiple possibilities for excitation. Regardless of the value of $k$ in $(7)$, i. e., whether the nuclei be excited on the centerband $(k=0)$ of $H_{1}$ or on a sideband $(k \neq 0)$, the nuclear induction signal still contains the whole set of frequencies (6). This signal has the frequency $\overline{\omega_{0}}$ only at the exact resonance $\omega_{1}+k \Omega=\bar{\omega}_{0}$ or for a free precession case. In the neighbourhood of the exact resonance the signal frequency is $\omega_{1}+k \Omega$ tather than $\bar{\omega}_{0}$. Then $(6)$ is altered to

$$
\omega^{\prime}(t)=\omega_{1}+k \Omega+\sum_{n=1}^{\infty} \omega_{0, n} \cos \left(n \Omega t-\varphi_{n}\right) .
$$

The pseudostationary magnetization of the probe $d V$ in the direction of the axis $x$, coinciding with the axis of the $B$-coil

$$
m_{x}=M_{\perp} \cos \left(\omega^{\prime}(t) t-k \varphi-\Phi_{\perp}\right),
$$

where $M_{\perp}$ is an amplitude of the transversal magnetization and $\Phi_{\perp}-$ its phase angle with respect to $\mathbf{H}_{1}(t)$.

The sample $d V$ during the course of its moving through the receiver coil $B$ produces magnetization pulses sensed by this coil. The periodicity of this pulsed magnetization (one denotes its amplitude by $M_{\perp}^{b}(t)$ ) enables once again a Fourier expansion of its to be written:

$$
M_{\perp}^{b}(t)=M_{\perp, 0}^{b}+\sum_{m=1}^{\infty} M_{\perp, m}^{b} \cos \left[m \Omega t-m\left(\varphi+\varphi_{a}\right)\right]
$$

with coefficients

$$
M_{\perp, 0}^{b}=M_{\perp} \frac{\varphi_{b}}{2 \pi} ; \quad M_{\perp, m}^{b}=\frac{M_{\perp}}{m \pi} \sin m \frac{\varphi_{b}}{2} .
$$

The $x$-component $m_{x}^{b}$ of that pulsed magnetization induces a signal in the $B$-coil

$$
d S^{\prime}=K_{b} d V \frac{d}{d t} m_{x}^{b}
$$

where $K_{b}$ is a nonsubstantial constant depending on coil geometry, its electrical parameters, etc. Substituting $m_{x}^{b}$ in (11) with the aid of (9) and $(10)$, it becomes

$$
\begin{gathered}
d S^{\prime}=K_{b} d V M_{\perp} \sum_{m=-\infty}^{\infty} \frac{\sin \left(m \varphi_{b} / 2\right)}{m \pi} \frac{d}{d t} \cos \left[\left(\omega^{\prime}(t)+m \Omega\right) t-\right. \\
\left.-(k+m) \varphi-m \varphi_{a}-\Phi_{\perp}\right] .
\end{gathered}
$$

In order to decode the role of $\omega^{\prime}(t)$ in (12) one substitutes it from (8), and after developing the arising product $\cos \left(n \Omega t-\varphi_{n}\right) t$, it reads 


$$
\begin{gathered}
d S^{\prime}=K_{b} d V M_{\perp} \sum_{m=-\infty}^{\infty} \frac{\sin \left(m \varphi_{b} / 2\right)}{m \pi} \frac{d}{d t} \cos \left\{\left[\omega_{1}+(k+m) \Omega\right] t+\right. \\
\left.+\sum_{n=1}^{\infty} \frac{\omega_{0, n}}{n \Omega_{i}}\left[\sin \left(n \Omega t-\varphi_{n}\right)-\sin \varphi_{n}\right]-(k+m) \varphi-m \varphi_{a}-\Phi_{\perp}\right\} .
\end{gathered}
$$

Formula (13) represents a set of phase modulated signals with multiple modulating frequencies $n \Omega(n=1 ; \ldots ; \infty)$ that produce a set of sidebands $n \Omega(n=-\infty ; \ldots ;-1 ; 1 ; \ldots ; \infty)$ having the same order of multiplicity.

If the gradients of the polarizing field are small as compared to the frequency of rotation, i. e. $\gamma H_{0, n} / n \Omega \ll 1$ or $\omega_{0, n} / n \Omega \ll 1$, one gets a set of nonmodulated signals

$$
\begin{aligned}
& d S^{\prime}=K_{b} d V M \perp \sum_{m=-\infty}^{\infty} \frac{\sin \left(m \varphi_{b} / 2\right)}{m \pi} \frac{d}{d t} \cos \left\{\left[\omega_{1}+(k+m) \Omega\right] t-\right. \\
& \left.-(k+m) \varphi-m \varphi_{a}-\Phi_{\perp}\right\} .
\end{aligned}
$$

This signal $d S^{\prime}$ is amplified, multiplied in a phase detector by a reference voltage $A \cos \left(\omega_{1} t+\Psi\right)$, and thereupon filtrated to remove the rf components. After taking the derivative in (14) the expression for the signal becomes:

$$
\begin{gathered}
d S=K_{d} d V M M_{\perp} \sum_{m=-\infty}^{\infty} \frac{\sin \left(m \varphi_{b} / 2\right)}{m \pi}\left[\omega_{1}+(k+m) \Omega\right] \sin [(k+m) \Omega t- \\
\left.-(k+m) \varphi-m \varphi_{a}-\Psi-\Phi_{\perp}\right],
\end{gathered}
$$

where $K_{d}$ is again a nonsubstantial constant containing $K_{b}$ and further parameters due to amplification, detection, etc., and $\Psi-$ a reference voltage phase angle with respect to $\mathbf{H}_{1}(t)$.

\section{Annular sample}

The sample has now the form of an annulet, and a continuous and uniform flow of sample particles through the $r f$ coils is established. The signal from the annular sample $S_{a}$ one can get by adding all the signals produced by differential volumes $d V$, each giving a signal $d S$ by (15). This is accomplished by integrating by $\varphi$ over the whole annulus:

$$
S_{a}=\int_{\varphi=0}^{2 \pi} d S(\varphi)
$$

where $d S(\varphi)$ is the same (15) with a substitution $d V=\operatorname{srd} \varphi$, where $s$ is a cross section area of the annulet and $r$ its medium radius. It turns out that most members in the arising sum vanish and only the members with $k+m=0$, i. e.,

$$
k=-m
$$

differ from zero. It leads to the following expression of the signal from an annular sample having a total volume $V$ :

$$
S_{a}=K_{d} \omega_{1} V M_{\perp} \frac{\sin \left(k \varphi_{b} / 2\right)}{k \pi} \sin \left(k \varphi_{a}-\Psi-\Phi_{\perp}\right) .
$$


Only one index appears in (17) and it is $k$ since it determines, as before, the resonance excitation given by $(7)$, but $m$ has lost its previous significance due to the uniform annular sample.

For further analyses instead of $M$ one introduces two magnetizations:

$$
M_{a}=M_{\perp} \cos \Phi_{\perp} \quad \text { and } \quad M_{d}=M_{\perp} \sin \Phi_{\perp},
$$

where the first generates an absorption signal and the second - a dispersion signal. Then (17) becomes

$$
S_{a}=K_{d \omega_{1}} V \frac{\sin \left(k \varphi_{b} / 2\right)}{k \pi}\left[M_{a} \cos \left(k \varphi_{a}-\Psi\right)+M_{d} \sin \left(k \varphi_{a}-\Psi\right)\right] .
$$

Using the usual formula for magnetization dependence on fractional detuning $T_{2}{ }^{*} \Delta \omega$ (from the exact resonance) and substituting a Fourier component of $H_{1}(t)$ from (3), corresponding to a particular $k$, for the amplitude of the $r f$ field, one gets

$$
M_{a} \sim \frac{T_{2}^{*} \frac{H_{1}^{c}}{k \pi} \sin k \frac{\varphi_{c}}{2}}{1+\left(T_{2}^{*} \Delta \omega\right)^{2}+\left(\gamma \frac{H_{1}^{c}}{k \pi} \sin k \frac{\varphi_{c}}{2}\right)^{2} T_{1} T_{2}^{*}},
$$

while $M_{d}$ differs from $M_{a}$ only by the multiplier $T_{2}^{*} \Delta \omega$. Now the final form of the signal expression can be written:

$$
S_{a}=K \frac{T_{2}^{*} \frac{H_{1}^{c}}{k^{2} \pi^{2}} \sin k \frac{\varphi_{b}}{2} \sin k \frac{\varphi_{c}}{2}\left[\cos \left(k \varphi_{a}-\Psi\right)+T_{2}^{*} \Delta \omega \sin \left(k \varphi_{a}-\Psi\right)\right]}{1+\left(T_{2}^{*} \Delta \omega\right)^{2}+\left(\gamma \frac{H_{1}^{c}}{k \pi} \sin k \frac{\varphi_{c}}{2}\right)^{2} T_{1} T_{2}^{*}} .
$$

Here the role of both $\varphi_{b}$ and $\varphi_{c}$ is exposed, and the coefficient $K$ contains all permanent parameters. By appropriate choice of the phase angle of the reference voltage one can alter $\Psi$ in $(20)$ and make $k \varphi_{a}-\Psi=0$ on a fixed sideband $k$. Then an absorption signal is observed on this sideband, while at $k \varphi_{a}-\Psi=\pi / 2$ a dispersion signal is present on the same sideband.

\begin{tabular}{|c|c|c|c|c|c|c|c|c|c|c|}
\hline \multirow{2}{*}{$\varphi_{a}$} & \multirow{2}{*}{$\Psi$} & \multicolumn{9}{|c|}{$k$} \\
\hline & & -4 & -3 & -2 & -1 & 0 & 1 & 2 & 3 & 4 \\
\hline 0 & $\begin{array}{c}0 \\
\pi / 2\end{array}$ & $\begin{array}{l}a \\
d\end{array}$ & $\stackrel{a}{d}$ & $\stackrel{a}{d}$ & $\begin{array}{l}a \\
d\end{array}$ & $\begin{array}{l}a \\
d\end{array}$ & $\begin{array}{l}a \\
d\end{array}$ & $\begin{array}{l}a \\
d\end{array}$ & $\begin{array}{l}a \\
d\end{array}$ & $\begin{array}{l}a \\
d\end{array}$ \\
\hline$\pi / 2$ & $\begin{array}{c}0 \\
\pi / 2\end{array}$ & $\begin{array}{l}a \\
d\end{array}$ & $\begin{array}{r}d \\
-a\end{array}$ & $\begin{array}{l}-a \\
-d\end{array}$ & $\begin{array}{r}-d \\
a\end{array}$ & $\begin{array}{l}a \\
d\end{array}$ & $\begin{array}{r}d \\
-a\end{array}$ & $\begin{array}{l}-a \\
-d\end{array}$ & $\begin{array}{r}-d \\
a\end{array}$ & $\begin{array}{l}a \\
d\end{array}$ \\
\hline$\pi$ & $\begin{array}{c}0 \\
\pi / 2\end{array}$ & $\stackrel{a}{d}$ & $\begin{array}{l}-a \\
-d\end{array}$ & $\begin{array}{l}a \\
d\end{array}$ & $\begin{array}{l}-a \\
-d\end{array}$ & $\begin{array}{c}a \\
d\end{array}$ & $\begin{array}{l}-a \\
-d\end{array}$ & $\begin{array}{l}a \\
d\end{array}$ & $\begin{array}{l}-a \\
-d\end{array}$ & $\begin{array}{l}a \\
d\end{array}$ \\
\hline $3 \pi / 2$ & $\begin{array}{c}0 \\
\pi / 2\end{array}$ & $\begin{array}{l}a \\
d\end{array}$ & $\begin{array}{r}-d \\
a\end{array}$ & $\begin{array}{l}-a \\
-d\end{array}$ & $\begin{array}{r}d \\
-a\end{array}$ & $\begin{array}{l}a \\
d\end{array}$ & $-d$ & $\begin{array}{l}-a \\
-d\end{array}$ & $\begin{array}{r}d \\
-a\end{array}$ & $\begin{array}{l}a \\
d\end{array}$ \\
\hline
\end{tabular}

Now one is to follow what the whole spectrum looks like at various angles $\varphi_{a}$ between the rf coils. If at a fixed $k k \varphi_{a}-\Psi=0$ holds, then at $(k+1)$ it becomes

$$
\cos \left[(k+1) \varphi_{a}-\Psi\right]=\cos \varphi_{a} ; \quad \sin \left[(k+1) \varphi_{a}-\Psi\right]=\sin \varphi_{a} .
$$


Starting with $\varphi_{a}=0$, corresponding to overlapping transmitter and receiver coils where still $\varphi_{b} \neq \varphi_{c}$ is possible, one can observe that all the lines in the spectrum are alike (having the same form and sign). Moreover, even a single coil system is possible, where $\varphi_{b}=\varphi_{c}$ essentially with the same spectrum. With $\varphi_{a}=\pi / 2 ; \pi ; 3 \pi / 2$ various alternate signal patterns are observed. For $k$ values from -4 to 4 some of them appear in Table, where $a$ denotes an absorption signal and $d-$ a dispersion signal.

\section{Experimental}

A low-field NMR spectrometer with $H_{0}=6.53 \mathrm{mT}$ (proton resonance at $278 \mathrm{kHz}$ ) was employed to get experimental spectra. The electromagnet consists of two coils in Helmholtz configuration, having outer diameter $75 \mathrm{~cm}$. This magnet supplies a polarizing field with inhomogeneity (maximal deviation from the mean value) as low as $5 \cdot 10^{-7}$ inside a sphere of volume $1 \mathrm{~cm}^{3}$ and $3 \cdot 10^{-5}$ inside a sphere of volume $20 \mathrm{~cm}^{3}$. A probe head with a spinning annular sample was constructed, and an air driven turbine is capable to rotate the sample at a rate as high as $850 \mathrm{rps}$ $\left(\Omega=5.3 \cdot 10^{3}\right)$ due to a rubber damped air bearing. The annular sample is of volume $V=2 \mathrm{~cm}^{3}$ with medium diameter of $3.2 \mathrm{~cm}$.
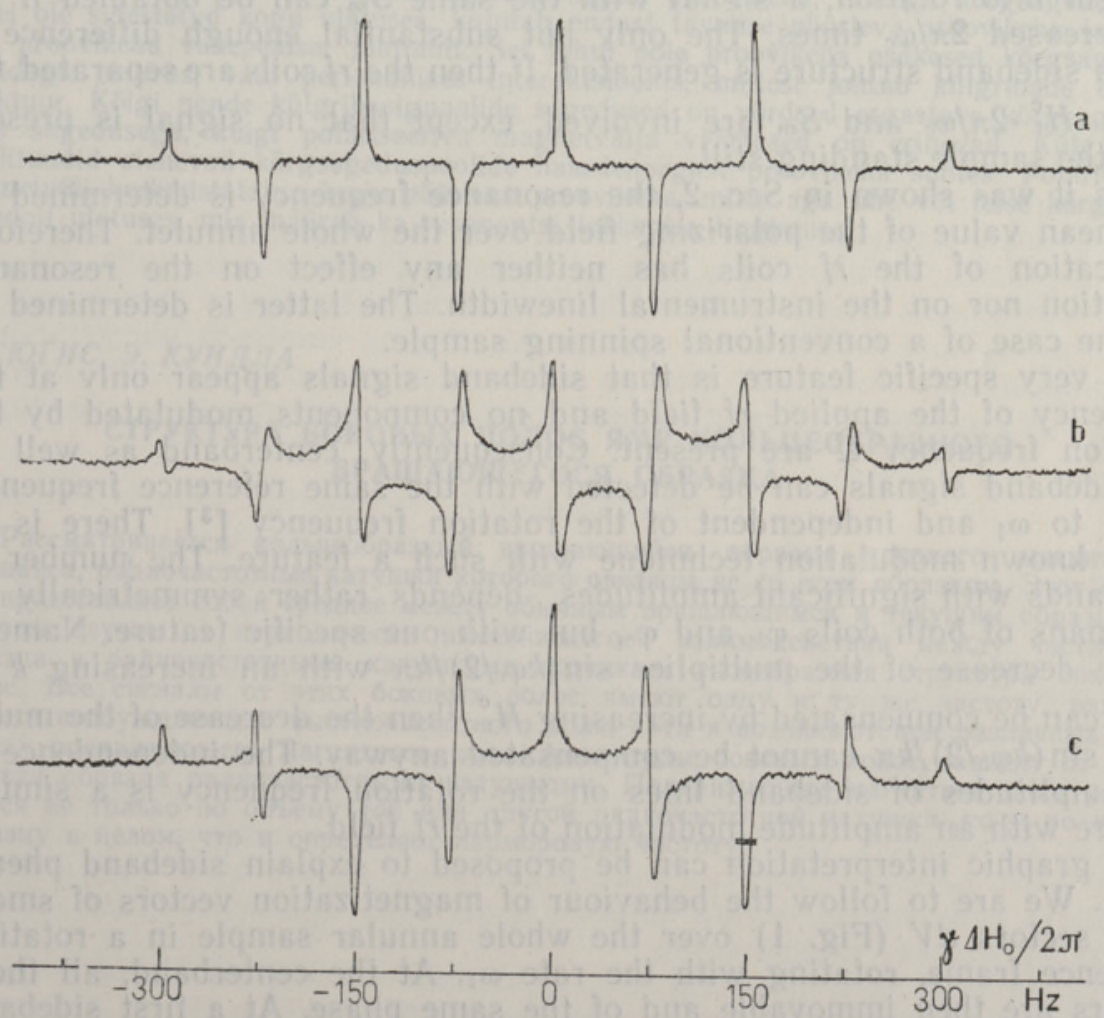

Fig. 2. Sideband spectra from annular spinning sample.

(a) $\varphi_{a}=\pi ; \Psi=0 ;$ (b) $\varphi_{a}=\pi ; \Psi=\pi / 2 ;$ (c) $\varphi_{a}=\pi / 2$; $\Psi=0$. Spinning rate is $75 \mathrm{rps}$.

The experimental spectra presented in Fig. 2 were obtained from a water sample with added paramagnetic ions to shorten $T_{2}$ down to $85 \mathrm{~ms}$. 
The spinning rate was $75 \mathrm{rps}$, giving the separation between the successive peaks actually the same $75 \mathrm{~Hz}$. The polarizing field was swept in the amount of $800 \mathrm{~Hz}$ during $800 \mathrm{~s}$, and a double time constant $0.5+0.5 \mathrm{~s}$ was used before the recorder. The spectra in Fig. 2, $a$ and $b$ correspond to the coils that are on the opposite sides of the annulet $\left(\varphi_{a}=\pi\right)$, while Fig. 2, $c$ represents a spectrum with coils at right angle $\left(\varphi_{a}=\pi / 2\right)$. The coils were identical with $\varphi_{b}=\varphi_{c}=0.35 \pi$. Further, the rf angle $\Psi$ is zero in the case of Fig. 2, $a$ and $c$ while it is equal to $\pi / 2$ in the case of Fig. 2, $b$.

It was verified, using very different spinning rates, that no dependence of the intensities of the individual peaks on the rotation frequency $\Omega$ is present.

\section{Conclusion}

The qualities of the NMR system with a uniform annular sample are to be outlined. Taking overlapping $r f$ coils $\left(\varphi_{a}=0\right)$ with the sample that is standing still, one supposes that a rf field with an amplitude $H_{1}^{c}$ produces a signal with a maximum amplitude $S_{m}$. If now the sample is brought into rotation, a signal with the same $S_{m}$ can be obtained if $H_{1}^{c}$ is increased $2 \pi / \varphi_{c}$ times. The only but substantial enough difference is that a sideband structure is generated. If then the $r f$ coils are separated, the same $H_{1}^{c} \cdot 2 \pi / \mathscr{Q}_{c}$ and $S_{m}$ are involved, except that no signal is present with the sample standing still.

As it was shown in Sec. 2, the resonance frequency is determined by the mean value of the polarizing field over the whole annulet. Therefore, dislocation of the rf coils has neither any effect on the resonance condition nor on the instrumental linewidth. The latter is determined as for the case of a conventional spinning sample.

A very specific feature is that sideband signals appear only at the frequency of the apolied $r f$ field and no components modulated by the rotation frequency $\Omega$ are present. Consequently, centerband as well as all sideband signals can be detected with the same reference frequency, equal to $\omega_{1}$ and independent of the rotation frequency $\left[{ }^{3}\right]$. There is no other known modulation technique with such a feature. The number of sidebands with significant amplitudes depends rather symmetrically on the spans of both coils $\varphi_{b}$ and $\varphi_{c}$, but with one specific feature. Namely, if the decrease of the multiplier $\sin \left(k \varphi_{c} / 2\right) / k \pi$ with an increasing $k$ in

(20) can be compensated by increasing $H_{1}^{c}$. then the decrease of the multiplier $\sin \left(k \varphi_{b} / 2\right) / k \pi$ cannot be compensated anyway. The independence of the amplitudes of sideband lines on the rotation frequency is a similar feature with an amplitude modulation of the rf field.

A graphic interpretation can be proposed to explain sideband phenomena. We are to follow the behaviour of magnetization vectors of small, fixed sectors $d V$ (Fig. 1) over the whole annular sample in a rotating reference frame, rotating with the rate $\omega_{1}$. At the centerband, all these vectors are then immovable and of the same phase. At a first sideband these vectors rotate at a rate exactly equalling $\Omega$, i. e., they make exactly one full revolution per rotation cycle, and they reappear in the transmitter coil close to the previous direction. Moreover, in every immovable cross section (actually this cross section slides over the annulet) these vectors have persistent phases, thus an immovable observer can see a persistent distribution of phases over the annulet in spite of the rotation of the individual vectors connected with the fixed sample 
sectors. It immediately leads to the conclusions that, firstly, nuclear magnetization can be excited by a rf field having the frequency $\omega_{1}$ and, secondly, the signal is induced in the receiver coil, again at the frequency $\omega_{1}$, although the actual resonance frequency is $\omega_{1}+\Omega$. Presented interpretation is easily expanded to higher sidebands.

\section{REFERENCES}

1. Hrynkiewicz A. Z., Wa lug a T., Acta Phys. Polon., 16, 381 (1957).

2. Бор один П. М., В сб.: ЯМР, вып. IV, под ред. П. М. Бородина, 1971.

3. С юг ис А. Ю., Па ст Я. О., К ундл а Э. И., Авт. свид. СССР № 495598 (1975).

\section{Academy of Sciences of the Estonian SSR,} Institute of Cybernetics

Received

Feb. 5, 1976

\section{A. SUGIS, E. KUNDLA}

\section{RONGAKUJULISE POORLEVA PROOVIKEHA TMR KULGRIBADE STRUKTUUR}

Rõngakujuline pöörlev tuumamagnetresonantsi proovikeha, millega kõrgsageduspoolid ei ole sidestatud kogu ulatuses, kujutab endast tavalise pöörleva proovikeha ja voolava proovikeha vahepealset juhtumit. Sel juhul pole proovikeha osakesed kōrgsageduspoolidega pidevas, vaid perioodilises interaktsioonis, millest johtub külgribade eriline struktuur. Kõigi nende külgribasignaalide sagedused on võrdsed ergastava kõrgsagedusvälja sagedusega, kuigi polariseeriva magnetvälja väärtused on erinevad. Külgribade amplituudid olenevad körgsageduspoolide haardenurgast proovikeha suhtes. Polariseeriv magnetväli keskmistatakse kogu pöörleva proovikeha, mitte aga ühe või teise kõrgsageduspooli ulatuses, mis määrab ka resonantsi tekkimise tingimuse.

\section{А. СЮГИС, Э. КУНДЛА}

\section{СТРУКТУРА БОКОВЫХ ПОЛОС ЯМР КОЛЬЦЕОБРАЗНОГО ВРАЩАЮЩЕГОСЯ ОБРАЗЦА}

Рассматривается кольцеобразный вращающийся образец ядерного магнитного резонанса, радиочастотные катушки которого связаны не со всем образцом. Этот образец представляет собой среднее между обычным вращающимся и текущим образцами. В этом случае от периодически изменяющегося взаимодействия между частицами образца и радиочастотными катушками возникает своеобразная структура боковых полос. Все сигналы от этих боковых полос имеют, одну и ту же частоту, равную частоте возбуждающего высокочастотного поля, хотя и возникают при различных значениях поляризующего магнитного поля. Амплитуды боковых полос зависят от угла захвата образца радиочастотными катушками. Поляризующее магнитное поле усредняется не только по объему той или другой радиочастотной катушки, но и по всему образцу в целом, что и определяет ларморовую частоту. 